\title{
Fomitopsis officinalis mushroom: ancient gold mine of functional components and biological activities for modern medicine
}

\author{
Waill A. Elkhateeb ${ }^{a}$, Ghoson M. Daba ${ }^{a}$, Marwa O. Elnahas ${ }^{a}$,
} Paul W. Thomas ${ }^{\mathrm{b}, \mathrm{c}}$

${ }^{a}$ Department of Chemistry of Natural and Microbial Products, Pharmaceutical Industries Researches Division, National Research

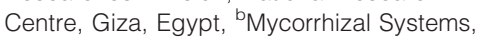
Mycorrhizal Systems Ltd, Lancashire, "Natural Science, University of Stirling, Stirling, UK

Correspondence to Assistant Professor, Dr / Waill Ahmed Elkhateeb, PhD, Department of Chemistry of Natural and Microbial Products, Pharmaceutical Industries Researches Division National Research Centre, El Buhouth Street, Dokki, Giza 12311, Egypt.

Tel: (+202) 33371635-33370933;

fax: (+202) 33370931;

e-mail: waillahmed@yahoo.com

Received: 9 September 2019

Accepted: 16 October 2019

\begin{abstract}
Polypore mushrooms have been used medicinally for thousands of years. Agarikon (Fomitopsis officinalis) is a medicinal polypore mushroom containing a host of pharmacologically active compounds that beneficially affect human health. Agarikon is known for its capability of producing various biologically active compounds with medical applications such as antiviral, antibacterial, anticancer, and anti-inflammatory agents. This review describes the importance of medicinal mushrooms, with a specific focus on Agarikon as an example of a globally commercialized medicinal mushroom.
\end{abstract}

\section{Keywords:}

Agarikon (Fomitopsis officinalis), biological activities, medicinal mushrooms, secondary metabolites, traditional medicine

Egypt Pharmaceut J 18:285-289

() 2019 Egyptian Pharmaceutical Journal $1687-4315$

Egyptian Pharmaceutical Journal 2019, 18:285-289

\section{Introduction}

Nature is considered an important source for the discovery of new medicines. A vast diversity of important biologically active compounds have arisen in the natural world, shaped by evolution and spanning a large diversity of species across different kingdoms [1]. In the fungi kingdom, medicinal (edible) mushrooms have long been used for the treatment of pathogens and disease. Furthermore, fungi show great potential as sources of antibacterial, antifungal, antiviral, anti-inflammatory as well as immunostimulant and antitumor agents [1-4].

Mushrooms have a rich history of use as food and medicine. As a group of macrofungi categorized as either ascomycetes or basidiomycetes, they may obtain their nutrition through saprotrophism, parasitism, symbiosis, or a combination of approaches. Mushrooms have a reproductive phase (fruiting bodies) and a vegetative phase (mycelia) [5,6]. Nowadays, medicinal mushrooms are regarded as functional foods and exist as over-the-counter health supplements used in complementary and alternative medicines $[7,8]$.

Several compounds are responsible for the therapeutic activities of many fungi genera; the main groups of these compounds are polysaccharides, terpenes, phenolic compounds, and essential amino acids, as well as minerals such as such as calcium, potassium, magnesium, iron, and zinc [6,9]. Polysaccharides represent the major compounds existing in medicinal mushrooms, and they exhibit antioxidant, anticancer, antidiabetic, anti-inflammatory, antimicrobial, antiviral, and immunomodulatory activities [6,10-13]. Glucan polysaccharides especially $\beta$-glucans have been reported to exhibit antimicrobial activity, are hypoglycemic, and are able to enhance immunity through the activation of macrophages [14-16]. Terpenes are the compounds responsible for the antioxidant, anticancer, and anti-inflammatory activities among many other biological activities exerted by mushrooms [5,17]. Phenolic compounds are responsible for antioxidant activities in mushroom extracts through acting as decomposers of peroxidase, inactivators of metals, oxygen scavengers, or inhibitors of free radicals [18]. On the contrary, mushrooms produce many bioactive proteins and peptides, such as lectins and laccases $[5,6]$. There are many genera of medicinal mushrooms known for their use as a source of therapeutic bioactive compounds. In this review, one of these species, Agarikon (Fomitopsis officinalis) is discussed in detail as an example of a promising source of therapeutic bioactive compounds.

This is an open access journal, and articles are distributed under the terms of the Creative Commons Attribution-NonCommercial-ShareAlike 4.0 License, which allows others to remix, tweak, and build upon the work non-commercially, as long as appropriate credit is given and the new creations are licensed under the identical terms. 


\section{Agarikon (Fomitopsis officinalis), a polyporus fungi}

Polypores are a group of fungi that develop fruiting bodies; they are characterized by the presence of hymenium (surface with a high density of sporebearing structures), consisting of multiple, small pores. Although their ecological categorization ranges from being pathogens to saprotrophs, they are often entirely dependent on wood as a substrate [19]. Polypores have been of great interest to those looking for novel medicinal compounds, owing to their rich history of medicinal use by various cultures [20]. $F$. officinalis (also known as Fomes officinalis, Agaricum officinalis, and Laricifomes officinalis) is a wooddecaying fungus in the family Polyporaceae and is commonly known as 'Agarikon.' The fruiting bodies are used as a popular source of medicine in North America, Western Europe, and Asia (including Mongolia) for the treatment of asthma, cough, gastric cancer, and pneumonia [21-23].

A rich literature base has dealt with $F$. officinalis ethnomycological aspects, but isolation and chemical characterization of single compounds has only recently been explored. According to several reports, there is indication of a broad-spectrum antibacterial and antiviral activity by $F$. officinalis, against pathogens like Mycobacterium tuberculosis and Staphylococcus aureus, as well as Orthopoxvirus [22,24,25]. Other biological activities of $F$. officinalis extracts include anticancer [21] and anti-inflammatory [26] activities.

\section{Fomitopsis officinalis ecology}

F. officinalis can grows as a parasite on a coniferous hosts, or as a saprobiont after the trees die where it causes brown rot $[27,28]$. Its carpophores are perennial and may last for more than 50 years; they are usually cylindrical or hoof shaped, and sometimes they may grow together to form irregular masses [29]. F. officinalis can be easily distinguished from other species by its chalky appearance as well as its specific bitter taste and odor in the earlier stage of growth [30]. The upper surface of the fruit body is rough and cracked, with a thin layer that is chalky white, creamy, or nut colored. As they age, the carpophores become darker in color and strongly cracked; its length can reach up to $50 \mathrm{~cm}$ or more [28].

F. officinalis fruit body appear at the initial site of infection, usually a few decades after the tree was first colonized [31]. The infection almost always takes place through heartwood that has been exposed through mechanical damage or through any burls found on the tree. After the fungal spores germinate, the mycelium grows into the woody interior, and from there develops a form of brown rot that starts cracks along the annual rings and rays and finally crumbles to develop small cubes [29]. This fungus species is distributed in the temperate zone, and it was reported in North America, Africa (Morocco), Asia (China, Korea, Japan, India, and Mongolia), and western Europe countries [28] (Fig. 1).

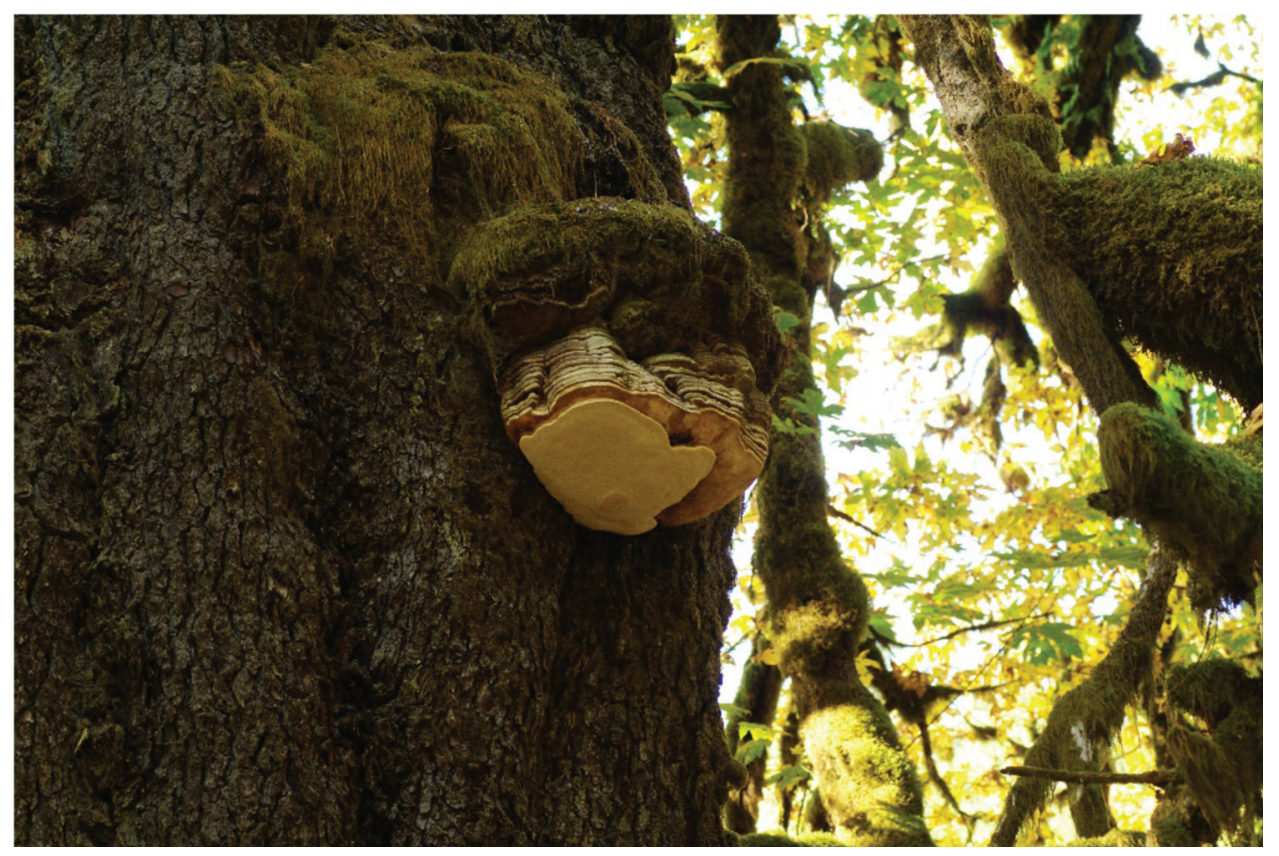

Agarikon (Fomitopsis officinalis) (photographs taken by Oluna and Adolf Ceska, Canada, hosted by http://mycoportal.org). 


\section{Agarikon natural products}

$F$. officinalis produces a variety of secondary metabolites such as eburicoic acid, sulfurenic acid, versisponic acid d, dehydroeburicoic acid, 3ketodehydrosulfurenic acid [32,33], fomefficinic acid a-e [34], fomefficinic acid $f, g$, dehydrosulfurenic acid, fomefficinol a-b, fomlactone a-c, laricinolic acid [21,35], agaric acid [36], fomitopsin a, officimalonic acids a-h [26], fomitopsin c [33], fomitopsin f, g, h, trypanocidal demalonyl fomitopsin $\mathrm{h}$, and trypanocidal fomitopsin $\mathrm{d}$ ethyl ester [37]. The majority of these compounds exert promising biological activities, such as antimicrobial. In previous phytochemical investigations on $F$. officinalis, drimane sesquiterpenoids [38], lanostane triterpenes with a 12,23-epoxy-26,23-lactone moiety [38,39], and chlorinated coumarins [24] have been reported, and the biological activity of the isolated compounds showed antiviral, anticancer, anti-inflammatory, and antituberculosis activities [37].

\section{Agarikon health benefits and medicinal actions}

Exploring the miraculous Agarikon mushroom for biological activities has resulted in many promising outcomes. Agarikon contains many pharmacologically active compounds that beneficially affect human health [40-42]. Several studies have reported biological activities of $F$. officinalis such as antibacterial activity, antiviral activity, anti-inflammatory activity, and antitumor activity.

\section{Antibacterial activity}

F. officinalis exhibits many vital biological activities. Chlorinated coumarin from mycelia has been used for the treatment of pulmonary diseases, especially tuberculosis and pneumonia, where it showed antibacterial activities toward $M$. tuberculosis and Bacillus pneumoniae as well as other microorganisms [25]. Parkash and Sharma [43] observed a variability in the efficiency of the aqueous and the ethanolic extracts when they were testing the effect of $F$. officinalis against some phytopathogenic microfungi (Curvularia lunata, Fusarium oxysporum, Alternaria solani, and Aspergillus terreus), as well as some bacteria (Bacillus subtilis and Escherichia coli). It was found that the pure ethanolic extract of $F$. officinalis inhibited the growth of $A$. solani and $A$. terreus completely, whereas $1: 4$ diluted extract was able to completely inhibit the growth of $C$. lunata and $F$. oxysporum. Moreover, the same results were reported using the aqueous extract where the growth of C. lunata and $F$. oxysporum was completely inhibited by $1: 4$ dilution of the aqueous extract. On the contrary, regarding the antibacterial activity. The pure ethanolic extract exhibited maximum inhibition activity toward E. coli, whereas 1: 4 dilution extract showed maximum activity against $B$. subtilis. Aqueous extract only showed inhibition activity toward $E$. coli when used in the $1: 4$ dilution. Thus the preparation of the extract plays an important role in the potential antimicrobial activity.

\section{Antiviral activity}

Medicinal mushrooms also show antiviral properties, which are helpful in preventing, reducing, or curing infection from various viruses [22]. The mycelium extract of $F$. officinalis has been found to have unique antiviral properties, including activity against the Orthopoxvirus, which is responsible for Smallpox [44]. Stamets [45] reported that $F$. officinalis extract (1-2\%) reduced the viral-induced cell damage by $50 \%$, whereas the diluted crude extract $\left(1: 10^{6}\right)$ reported a great efficacy against several viruses including herpes, influenza $A$, and influenza B. Moreover, the aqueous extract of $F$. officinalis showed antiviral activities against human influenza (H3N2) and bird influenza (H5N1) [46].

\section{Anti-inflammatory activity}

$F$. officinalis shows another biological application as an anti-inflammatory agent. Its methanolic extract was able to reduce the production of nitric oxide (NO), which is implicated in several inflammatory diseases including asthma. Han et al. [26] reported methyllanostane triterpenes of diverse structures, which were able to inhibit NO production in lipopolysaccharidestimulated RAW264.7 cells, hence reducing the inflammation process. Moreover, it was reported that Agarikon treats musculoskeletal pain owing to its anti-inflammatory properties when applied topically as a poultice [44].

\section{Antitumor activity}

Full clinical trials are costly in time and resources, and consequently, fungal extracts efficiency in preventing and treating cancer is still largely unproven. More and rigorous investigation is essential to explore this complex topic further. Nevertheless, there is some promising evidence, indicating that the consumption of some fungal extracts helps in protecting against some cancers types, specially breast and gastrointestinal $[47,48]$.

Lanostane-type triterpenoids, which was reported in $F$. officinalis extract, showed anticancer activity [21]. It was found to inhibit eukaryotic DNA polymerase, a feature which allows it to be a cytotoxic agent and helpful as a cancer chemotherapeutic agent [49].

$\mathrm{Wu}$ et al. [50] reported that the ethanol extracts of $F$. officinalis exhibit stronger anticancer activities than that 

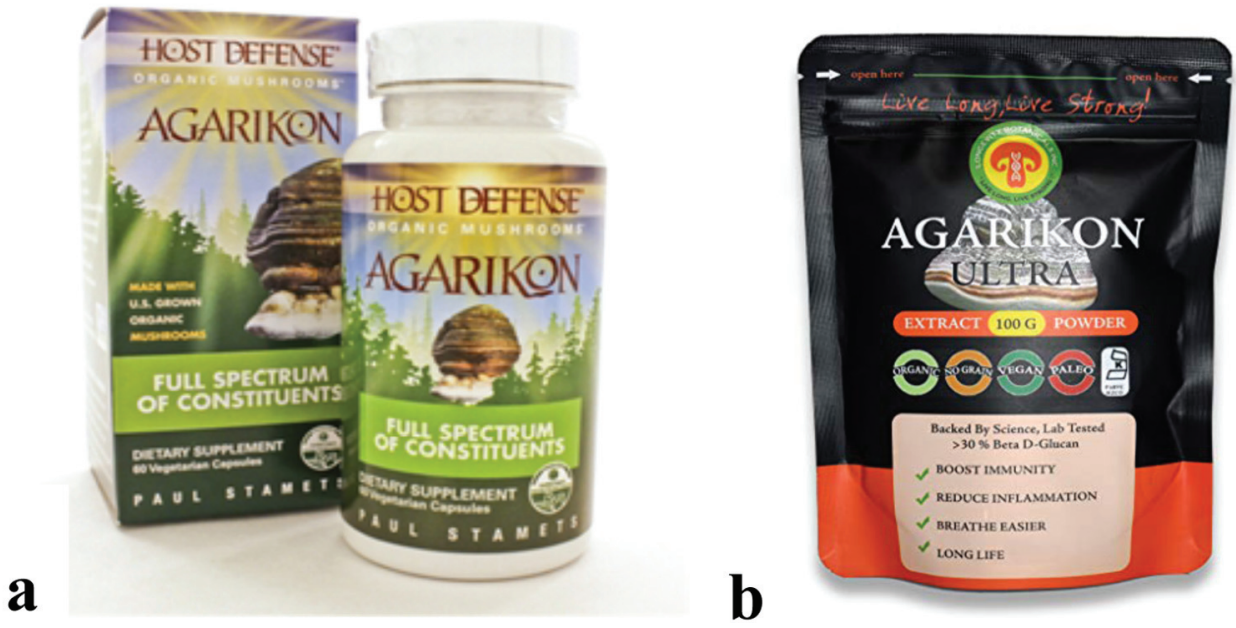

Products containing Agarikon (Fomitopsis officinalis) extract (a). F. officinalis supplement tablets (http://www.camformulas.co) (b). F. officinalis powder (http://www. binge.bh).

of water extracts toward human breast cancer (MDAMB-231) cells, hepatoma (HepG2), colon cancer (HCT-116), lung cancer (A549), and mouse sarcoma 180 cells (S-180). This was evaluated by 3(4,5-dimethylthiazol-2-yl)-2,5-diphenyltetrazolium bromide assays (MTT assay), which is a colorimetric assay used to measure cell viability before and after being treated with the fungal extract. The results showed that the maximum anticancer activity was shown toward HCT-116, where the cell viability using MTT assay was only $15.7 \pm 4.0 \%$ at a concentration of $50 \mu \mathrm{g} / \mathrm{ml}$ after $24 \mathrm{~h}$ of incubation.

The intense global interest and value assigned to $F$. officinalis has led to commercial products derived from this valuable medicinal mushroom, as shown in Fig. 2.

\section{Global market of Agarikon}

Unfortunately, Agarikon grows very slowly and is rarely found, which made its use as a supplement very challenging. This problem encourages culturing of Agarikon using submerged techniques or cultivation in the boreal nature to cover demands of this marvel mushroom. Figure 2 illustrates some products based on Agarikon extracts.

\section{Conclusion}

Globally, there is a rich history of foods being used as medicine. One such kind of traditional therapy that was commonly used consists of mushrooms with medicinal properties. There are several edible mushrooms that have significant medicinal metabolites, whereas there are other species that may not be used as food but are valued solely for their medicinal properties. F. officinalis is one such species and contains various active compounds which makes it of great interest from a biological and pharmacological perspective.

Several studies have presented promising activities of $F$. officinalis. Many of those studies use relatively crude extracts of $F$. officinalis, and some have confirmed the existence of biological activities of $F$. officinalis, such as antiviral, antibacterial, anticancer, and antiinflammatory. Further research is required to isolate and identify more bioactive compounds responsible for such biological activities. The relative efficiency of $F$. officinalis in comparison to other medicinal species remains to be elucidated and would be a fertile topic for further investigation.

\section{Financial support and sponsorship Nil.}

\section{Conflicts of interest}

There are no conflicts of interest.

\section{References}

1 Blagodatski A, Yatsunskaya M, Mikhailova V, Tiasto V, Kagansky A, Katanaev VL. Medicinal mushrooms as an attractive new source of natural compounds for future cancer therapy. Oncotarget 2018; 9:29259.

2 Lindequist $U$, Teuscher E, Narbe G. New active ingredients from Basidiomycetes. Z Phytother 1990; 11:139-149.

3 Brandt CR, Piraino F. Mushroom antivirals. Recent Res Dev Antimicrob Agents Chemother 2000; 4:11-26.

4 Chihara G, Maeda Y, Hamuro J, Sasaki T, Fukuoka F. Inhibition of mouse sarcoma 180 by polysaccharides from Lentinus edodes (Berk.) sing. Nature 1969; 222:687. 
5 Sánchez C. Bioactives from mushroom and their application. In Munish Puri. Food bioactives. Cham: Springer; 2017; 23-57

6 Elkhateeb WA, Daba GM, Thomas PW, Wen TC. Medicinal mushrooms as a new source of natural therapeutic bioactive compounds. Egypt Pharmac $J$ 2019a; 18:88-101.

7 Rathee S, Rathee D, Rathee D, Kumar V, Rathee P. Mushrooms as therapeutic agents. Braz J Pharmacol 2012; 22:459-474.

8 Ayeka PA. Potential of mushroom compounds as immunomodulators in cancer immunotherapy: a review. Evid Based Complement Altern Med 2018; 2018:7271509.

9 Petrovska B. Protein fraction of edible Macedonian mushrooms. Eur J Food Sci Technol 2001; 212:469-472.

10 Kozarski M, Klaus A, Niksic M, Jakovljevic D, Helsper JP, Van Griensven LJ. Antioxidative and immunomodulation activities of polysaccharide extracts of the medicinal mushrooms Agaricus bisporus, Agaricus brasiliensis, Ganoderma lucidum and Phellinus linteus. Food Chem 2011; 129:1667-1675.

11 Friedman M. Mushroom polysaccharides: chemistry and antiobesity, antidiabetes, anticancer, and antibiotic properties in cells, rodents, and humans. Foods 2016; 5:80.

12 Wei H, Yue S, Zhang S, Lu L. Lipid-lowering effect of the Pleurotus eryngii (king oyster mushroom) polysaccharide from solid-state fermentation on both macrophage-derived foam cells and zebrafish models. Polymers 2018; 10:492.

13 Elkhateeb WA, Daba GM, Elmahdy EM, Thomas PW, Wen T-C., Mohamed NS. Antiviral potential of mushrooms in the light of their biological active compounds. ARC J Pharmac Sci 2019b; 5:8-12.

14 Batbayar S, Lee DH, Kim HW. Immunomodulation of fungal b-glucan in host defence signaling by dectin-1. Biomol Therapeut 2012; 20:433-445.

15 Yang $\mathrm{Y}$, Zhao $\mathrm{X}$, Li J, Jiang $\mathrm{H}$, Shan $\mathrm{X}$, Wang $\mathrm{Y}$, et al. A $\beta$-glucan from Durvillaea Antarctica has immunomodulatory effects on RAW264.7 macrophages via toll-like receptor 4. Carbohydr Polym 2018; 191:255-265.

16 Minato KI, Laan LC, van Die I, Mizuno M. Pleurotus citrinopileatus polysaccharide stimulates anti-inflammatory properties during monocyteto-macrophage differentiation. Int J Biol Macromol 2019; 122:705-712.

17 Ruan W, Popovich DG. Ganoderma lucidum triterpenoid extract induces apoptosis in human colon carcinoma cells (Caco-2). Biomed Prev Nutr 2012; 2:203-209.

18 Dziezak JD. Antioxidants - the ultimate answer to oxidation. Food Technol 1986; 40:94.

19 Gilbert GS, Ferrer A, Carranza J. Polypore fungal diversity and host density in a moist tropical forest. Biodiv Conserv 2002; 11:947-957.

20 Ryvarden L. Tropical polypores. British Mycological Society Symposium Series, Cambridge: Cambridge University Press; 1993.

$21 \mathrm{Wu} X$, Yang JS, Yan M. Four new triterpenes from fungus of Fomes officinalis. Chem Pharm Bull 2009; 57:195-197.

22 Stamets PE. Antiviral and antibacterial activity from medicinal mushrooms. US Patent 8,765,138 B2, 2014.

23 Grienke U, Zöll M, Peintner U, Rollinger JM. European medicinal polyporesa modern view on traditional uses. J Ethnopharmacol 2014; 154:564-583.

24 Hwang CH, Jaki BU, Klein LL, Lankin DC, McAlpine JB, Napolitano JG, et al. Chlorinated coumarins from the polypore mushroom Fomitopsis officinalis and their activity against Mycobacterium tuberculosis. J Natl Prod 2013; 76:1916-1922.

25 Girometta C. Antimicrobial properties of Fomitopsis officinalis in the light of its bioactive metabolites: a review. Mycology 2019; 10:32-39.

26 Han J, Li L, Zhong J, Tohtaton Z, Ren Q, Han L, et al. Officimalonic acids $\mathrm{A}-\mathrm{H}$, lanostane triterpenes from the fruiting bodies of Fomes officinalis. Phytochemistry 2016; 130:193-200.

27 Holsten EH. Insects and diseases of Alaskan forests. Alaska Region: US Dept. of Agriculture, Forest Service; 2001.
28 Pietka J, Szczepkowski A. Localities of Fomitopsis officinalis in Poland. Acta Mycol 2004; 39:33-45.

29 Pi凶tka J, Grzywacz A. In situ inoculation of larch with the threatened wooddecay fungus Fomitopsis officinalis (Basidiomycota) - experimental studies. Pol Bot J 2005; 50:225-231.

30 Ryvarden L, Melo I. Poroid fungi of Europe. Synopsis Fungorum. 2014; 31:1-455.

31 Konev G. Gribnye bolezni kedra sibirskogo. Lesnoe Chozjajstvo 1972; 9:67.

$32 \mathrm{Wu}$ X, Yang JS, Dong YS. Chemical constituents of Fomes officinalis (I). Chin Tradit Herb Drugs 2005; 36:811-814.

$33 \mathrm{Shi} \mathrm{ZT}$, Bao HY, Feng S. Antitumor activity and structureactivity relationship of seven lanostane-type triterpenes from Fomitopsis pinicola and $F$. officinalis. China J Chin Mater Med 2017; 42:915-922.

34 Wu X, Yang JS, Zhou L, Dong YS. New lanostane-typetriterpenes from Fomes officinalis. Chem Pharm Bull 2004; 52:1375-1377.

35 Feng W, Yang J, Xu X, Liu Q. Quantitative determination of lanostane triterpenes in Fomes officinalis and their fragmentation study by HPLC-ESI. Phytochem Anal 2010; 21:531-538.

36 Airapetova AY, Gavrilin MV, Dmitriev AB, Mezenova TD. Examination of the structure of agaricinic acid using $1 \mathrm{H}$ and 13C NMR spectroscopy. Pharma Chem J 2010; 44:510-513.

37 Naranmandakh S, Murata T, Odonbayar B, Suganuma K, Batkhuu J, Sasaki K. Lanostane triterpenoids from Fomitopsis officinalis and their trypanocidal activity. J Natl Med 2018; 72:523-529.

38 Feng W, Yang JS. A new drimane sesquiterpenoid and a new triterpene lactone from fungus of Fomes officinalis. J Asian Natl Prod Res 2015; 17:1065-1072.

39 Epstein WW, Sweat FW, VanLear G, Lovell FM, Gabe EJ. Structure and stereochemistry of ofcinalic acid, a novel triterpene from Fomes officinalis. J Am Chem Soc 1979; 101:2748-2750.

40 Zjawiony JK. Biologically active compounds from Aphyllophorales (polypore) fungi. J Natl Prod 2004; 67:300-310.

41 De Silva D, Rapior S, Sudarman E, Stadler M, Jianchu XU, Aisyah A, Kevin D. Bioactive metabolites from macrofungi: ethnopharmacology, biological activities and chemistry. Fungal Div 2013; 62:1-40.

42 Jayachandran $\mathrm{M}$, Xiao J, Xu B. A critical review on health promoting benefits of edible mushrooms through gut microbiota. Int $\mathrm{J}$ Mol Sci 2017; 18:1934.

43 Parkash V, Sharma A. In vitro efficacy of bracket fungi for their potential antimicrobial activity. J Microbiol Biotechnol Food Sci 2016; 6:818.

44 Stamets PE. Antiviral activity from medicinal mushrooms. Google patents; 2011.

45 Stamets PE. Antiviral activity from medicinal mushrooms and their active constituents. Google patents; 2018.

46 Teplyakova TV, Psurtseva NV, Kosogova TA, Mazurkova NA, Khanin VA, Vlasenko VA. Antiviral activity of polyporoid mushrooms (higher Basidiomycetes) from Altai Mountains (Russia). Int J Med Mushrooms 2012; 14:37-45.

$47 \mathrm{Kim}$ HJ, Chang WK, Kim MK, Lee SS, Choi BY. Dietary factors and gastric cancer in Korea: a case-control study. Int J Cancer 2002; 97:531-535.

48 Hara M, Hanaoka T, Kobayashi M, Otani T, Adachi HY, Montani A, et al. Cruciferous vegetables, mushrooms, and gastrointestinal cancer risks in a multicenter, hospital-based case-control study in Japan. Nutr Cancer 2003; 46:138-147.

49 Akihisa T, Mizushina Y, Ukiya M, Oshikubo M, Kondo S, Kimura Y, et al. Dehydrotrametenonic acid and dehydroeburiconic acid from Poria cocos and their inhibitory effects on eukaryotic DNA polymerase $\alpha$ and $\beta$. Biosci Biotechnol Biochem 2004; 68:448-450.

$50 \mathrm{Wu}$ HT, Lu FH, Su YC, Ou HY, Hung HC, Wu JS, et al. In vivo and in vitro anti-tumor effects of fungal extracts. Molecules 2014; 19:2546-2556. 